\title{
RESENHA DE CUENTOS DE MADUREZ, DE MACHADO DE ASSIS
}

\author{
REVIEW OF CUENTOS DE MADUREZ, \\ BY MACHADO DE ASSIS
}

\begin{abstract}
ASSIS, Joaquim Maria Machado de. Cuentos de madurez. Edición, traducción, notas y prólogo de Bethania Guerra de Lemos y Juan Bautista Rodríguez. Valencia: Editorial Pré-Textos, 2011.
\end{abstract}

Melânia Silva de Aguiar

Pontifícia Universidade Católica de Minas Gerais

Belo Horizonte (MG), Brasil

Quando Sílvio Romero, em fins do século XIX, escreveu sua crítica sobre a obra até então publicada de Machado de Assis, não poderia prever que alguns dos traços do escritor, por ele vistos como negativos, seriam exatamente aspectos, dentre outros, que estudiosos da literatura brasileira, posteriores a ele, apontariam como grandes qualidades do autor. Entre esses traços negativos, encontra-se a crítica de Sílvio ao "estilo plácido e igual", com ideias retorcidas, repisadas, "resultado de uma lacuna do romancista nos órgãos da palavra, sugerindo um "tal ou qual tartamudear"; humour artificial, um capricho, "uma cousa feita segundo certas receitas e manipulações"; pessimismo intensificado nas últimas obras com "fórmulas meramente convencionais" etc.

Antonio Candido, em seu "Esquema Machado de Assis", repassando nas gerações sucessivas de críticos modos distintos de ler Machado, ressalta os aspectos privilegiados nessas leituras e, a partir daí, o quanto havia e há de moderno na produção machadiana, sobretudo por sua aproximação com tendências vanguardistas do século XX. São alguns desses aspectos apontados por Candido: a sugestão do todo pelo fragmento, da estrutura pela elipse, da emoção pela ironia, da grandeza pela banalidade. E ainda: a presença, em alguns romances, da inconclusão ou da abertura, a possibilitar uma leitura dupla; o uso de estilo empolado e um tanto precioso, "forma sutil de 
negaceio, como se o narrador estivesse rindo um pouco do leitor"; a revelação de tormentos do homem e iniquidades do mundo "sob um aspecto nu e sem retórica, agravados pela imparcialidade estilística".

Festejado por seus contemporâneos, apesar das aguilhoadas de Sílvio Romero e de alguns outros, poucos, Machado ficaria, no entanto, circunscrito ao reconhecimento doméstico, sendo a barreira da língua elemento cerceador de peso nesse isolamento geográfico imerecido de seus escritos. Hélio de Seixas Guimarães, em seus estudos sobre a recepção crítica de Machado de Assis, traz informações sobre certo reconhecimento internacional do autor ao longo do século $\mathrm{XX}$, sobretudo da parte de leitores e críticos anglo-americanos; entre os latinos, lembra traduções para o castelhano de romances machadianos, contemporâneas do autor (em Montevidéu e Buenos Aires) ou mais recentes (Espanha), mas ressalta o quão restrita foi e é a circulação dessas traduções e quão escassas são as notícias sobre a recepção crítica dessas obras.

O livro Cuentos de madurez, lançado em 2011 em bela e cuidada edição da Editorial Pré-textos, de Valência, Espanha, constituído de trinta contos machadianos cuidadosamente selecionados e competentemente traduzidos para o espanhol, representa um importante passo a mais no sentido da divulgação da obra de nosso escritor maior. Publicado com o apoio do Ministério da Cultura do Brasil / Fundação Biblioteca Nacional / Coordenadoria do Livro e da Leitura, o empreendimento contou com o trabalho dedicado de Bethania Guerra de Lemos e Juan Bautista Rodríguez, responsáveis pela edição, tradução, notas e pelo prólogo da obra.

Não pode ter sido tarefa das mais simples para os organizadores selecionar em universo tão vasto e tão rico, qual seja o da produção contística de Machado de Assis, as peças que deveriam figurar nessa edição. O critério adotado - e um critério norteador, seguro, tem de existir, por força, quando se trata de realizar uma antologia - fica bastante claro nas páginas introdutórias da obra, e até mesmo no título, de feliz acerto, Cuentos de madurez. Tomando como marco ou ponto de partida a data de 1881, ano de publicação do romance Memórias póstumas de Brás Cubas, foram selecionados pelos organizadores, dentre as peças que constituíram as antologias posteriores a essa data e organizadas pelo próprio Machado, "treinta cuentos representativos de su período de mayor fecundidad y madurez", mantendo-se aí a distribuição cronológica realizada pelo 
autor. Somente o conto "O machete" (na tradução, "El guitarrico"), publicado em 1878 no Jornal das Famílias, segundo nos esclarecem os organizadores, portanto anterior à data fixada, foi incorporado à antologia, por ser considerado, em muitos sentidos, "como el punto de inflexión para su nueva etapa creativa."

Arrolar nessa resenha os trinta títulos dos contos selecionados é aqui tarefa dispensável; basta informar que no livro estão presentes alguns dos contos mais famosos e reconhecidamente mais valiosos de Machado; daí ter-nos parecido acertado o critério adotado, ou seja, o da seleção dos contos produzidos no período de maior maturidade do autor. Alguns desses contos são mesmo "antológicos", ou seja, têm de figurar obrigatoriamente em qualquer antologia de contos machadianos. Podem ser aqui lembrados: "O espelho", "A igreja do diabo", "Noite de almirante", "O enfermeiro", "A cartomante", "Uns braços", "Um apólogo", "Missa do galo", para só ficar em alguns.

Se, como os organizadores do livro afirmam no prólogo (a que dão o título de "Las ficciones del brujo"), Machado, inquilino de Yesod, assim classificado a partir de Harold Bloom, "nos sirve en bandeja de plata las tripas y los misterios enmarañados del alma humana", pode-se dizer que também em bandeja de prata nos são servidos esses contos machadianos. Vertidos ao espanhol, eles vêm agradavelmente distribuídos no livro de quatrocentas páginas, alinhadas, claras e escorreitas, costuradas e firmes, acrescidas de fitinha marcadora vermelha, acetinada, e emolduradas por capa dura de desenho irretocável e, ainda, pela cobertura sobressalente, protetora: tudo, de refinado bom gosto.

Nesse prólogo, buscando dar ao leitor uma visão de conjunto da antologia, os organizadores ensaiaram uma espécie de tipologia dos contos, a partir dos temas ou do tratamento dado às "doenças da alma", preocupação presente, segundo eles, sobretudo nos contos da maturidade, a ponto de converter-se em núcleo de muitas dessas histórias. Assim, a inveja, o remorso, os ardis, as traições, a loucura, a fantasia, a dúvida são algumas das "doenças" aqui mencionadas. A mulher, vista como "necesidad y narcótico", ou como "vértice de un triángulo"; a tísica, "embajadora de la muerte"; a música, como pano de fundo de algumas das peças, são outros tantos elementos integrantes das narrativas, aqui registrados nessa introdução panorâmica. Uma curta errata acompanha o livro, retificando pequenos equívocos do prólogo. 
Todo ato tradutório implica tropeços, obstáculos às vezes intransponíveis, e isso não terá sido diferente para os tradutores desses contos machadianos. Se traduzir fosse apenas um ato linguístico, as dificuldades seriam certamente menores; mas traduzir textos implica "traduzir culturas", conhecer na intimidade vocábulos e expressões e seu papel e lugar no universo cultural em que se dão, sem no entanto perder de vista o leitor, nem sempre familiarizado com esse universo e o modo como ele nos é apresentado.

As notas de pé de página elaboradas pelos autores esclarecem muitas das passagens dos contos, como, entre outras, as que se referem à história do Brasil, a nomes e localização de bairros do Rio de Janeiro, a costumes antigos ou a cargos já inexistentes no mundo atual. Mas o embate maior se dá mesmo no corpo do texto, palco das sutilezas muitas vezes intraduzíveis, por mais rica que seja a língua de destino, como o espanhol sabidamente o é.

Em se tratando de Machado de Assis, se se levarem em conta as observações de Antonio Candido acima expostas, as dificuldades de tradução crescem, pelo que há de inconcluso, de "tartamudeio", de sentidos ocultos, de preciosidades estilísticas, no fundo zombeteiras, sob a aparente banalidade, neutralidade ou inocência do discurso, atento, de fato, às questões mais sérias e mais profundas da alma humana.

Para comentar um aspecto dessas dificuldades, tomemos como exemplo "Um apólogo", um dos contos traduzidos e apresentados nesses Cuentos de madurez. Publicado pela primeira vez na Gazeta de Notícias do Rio de Janeiro com o título "A agulha e a linha", foi incluído em 1896 no livro de contos Várias histórias, com o novo título. Aí, em poucas linhas, nos é posta diante dos olhos uma cena de ambiência doméstica, em que as personagens, movidas pela vaidade, representam o velho drama universal dos desajustes humanos, ou seja, o desejo de mais valia, a busca de reconhecimento, de sucesso e, mais, a sedução do luxo e dos prazeres mundanos. Se atentarmos em pequenos sinais emitidos pelo texto, damo-nos conta da riqueza de sentimentos e de intenções que povoam esse universo eminentemente feminino, constituído de agulha, linha (a noção de masculino do nome "novelo" perde-se no conto, se comparada à predominância do feminino representado em "linha"), uma costureira, uma baronesa, uma caixinha de costura. Como espectadores, um alfinete, um professor 
de melancolia e um narrador de terceira pessoa que, repentinamente, se torna personagem, intrometendo-se na história e atualizando o tempo da narrativa ao introduzir nela seu próprio tempo: "Contei esta história a um professor de melancolia [...]". Perde-se, pois, a essa altura do conto, aquela impessoalidade dos narradores heterodiegéticos, e ganha-se em dimensão humana, no lamento que a frase sugere, reforçado esse lamento no trecho final do conto, agora pela voz do dito professor: "Também eu tenho servido de agulha a muita linha ordinária". Fica aí expressa uma queixa que pode ser também do narrador, identificado a esse professor que tem a ensinar nada mais, nada menos que "melancolia".

A prevalência do feminino no texto é sintomática: afinal, a disputa entre a agulha e a linha é uma disputa tipicamente feminina, doméstica, embora o que a desencadeie, a vaidade, não seja nada estranha aos homens. O que há de feminino nessa disputa são as pequenas "alfinetadas" (para não sair do terreno da costura), as "picuinhas" malévolas, "qualidades" que, injustamente ou não, são atribuídas às mulheres. Assim, à sabedoria do alfinete, sinalizada por sua grande cabeça e não menor experiência, contrapõe-se a falta de cabeça da agulha, "tola" que é, sempre em desvantagem na discussão, que ela mesma provoca. A linha (ou o novelo de linha), mais sábia, olha à distância sua rival, tratando-a com superioridade, sem dar maior importância a seus ataques.

$\mathrm{Na}$ exemplar tradução do conto ("Un apólogo", p. 357-360), observe-se a "solução" encontrada pelos tradutores para "novelo de linha" na passagem para o espanhol: "carrete de hilo". Enquanto no original, o "novelo de linha", tratado pela agulha, sem nenhuma cerimônia, por "tu", tornando-se mais à frente "senhora linha", na ironia tolamente superior da agulha, na tradução, à mesma altura, ganha terreno o "señor hilo", como se vê em:

- Y ahora, señor hilo, ¿aún insistes en lo que decías hace poco? ¿No te das cuenta de que esta distinguida costurera sólo se preocupa por mí? Soy yo quien va aquí en sus dedos, pegadita a ellos, agujereando arriba y abajo... 
Perdeu-se, pois, aí, na tradução, o detalhe do gênero, o feminino das "picuinhas" e das mútuas alfinetadas, embora de "alfinete" as duas rivais só tivessem mesmo a proximidade textual com esse sábio (e masculino) "alfiler de cabeza grande y no poca experiencia", conselheiro da "pobre aguja". Outra escolha para "linha" teria sido possível? Ou melhor?

Mas isso é só um detalhe; um pequenino exemplo dos tais tropeços mencionados, gotinhas d'água no rico e instigante caudal de soluções encontradas pelos tradutores nesse excelente Cuentos de madurez, iniciativa para ser comemorada, por sua relevância para a divulgação e perpetuação da memória de Machado de Assis fora dos muros nacionais.

Melânia Silva de Aguiar é professora titular de Literatura Brasileira da Faculdade de Letras da UFMG (aposentada) e professora no Programa de Pós-graduação em Letras da PUC Minas; estudiosa da poesia do século XVIII e do memorialismo em Minas Gerais, coordena o Grupo de Estudos de Poesia da Modernidade (GEPOM), na PUC Minas, e desenvolve atualmente o projeto "Poesia e realidade na América Latina", com apoio da FAPEMIG. E-mail: <melania.bh@terra.com.br> 